\title{
EVALUATION OF LEAN PRINCIPLES IN BUILDING MAINTENANCE MANAGEMENT
}

\author{
Isabela S. Dragone ${ }^{1}$, Clarissa N. Biotto², and Sheyla M. B. Serra ${ }^{3}$
}

\begin{abstract}
Buildings do not usually receive the necessary maintenance during their use, which may cause serious accidents. Building maintenance is essential for ensuring the project's planned performance, safety, and functionality during the phase of use and occupation, which are ensured by the maintenance management. However, with the increasing complexity of buildings, the traditional maintenance management methods have become outdated. The lean mentality is shown as a viable alternative since it is possible to apply it in building maintenance through its principles and practices. The research strategy adopted was the case study carried out in a building maintenance company. A lean maintenance checklist was created, composed of 46 practices grouped in the five lean principles, which support identifying the level of lean maintenance deployed in the activities and processes of building maintenance management adopted by the company.
\end{abstract}

\section{KEYWORDS}

Lean construction, lean maintenance, building maintenance management, construction industry.

\section{INTRODUCTION}

Buildings must have adequate conditions for use, necessary maintenance to prevent accidents caused by failures or wear of use/operation, and ensure its conservation and satisfactory performance throughout its useful life (Carlino, 2012).

There are three stages in the life cycle of buildings, as suggested by Lessa and Souza (2010). The first stage is related to study and to plan activities, such as viability, studies, and design documentation development. The second encompasses the activities related to the execution of the construction and assembly of buildings, and the third is the stage of use, operation, and maintenance.

Akcamete, Akinci and Garrett (2010) point out that the largest share of expenses within the building's life cycle occurs in the last stage, representing approximately $60 \%$ of all the costs involved. Furthermore, these authors indicate that corrective maintenance, which acts after the deterioration mechanism occurs, corresponds to this cost's more significant portion. The consequences of the lack of building maintenance, or its inadequate application, entails risks in its users' safety, no guarantee of the building

Graduate Student, Civil Engineering Department, Federal University of Sao Carlos (UFSCar), Brazil, isabeladragone@estudante.ufscar.br, orcid.org/0000-0001-8945-5754

2 Post-Doctoral Researcher, Postgraduate Programme of Civil Engineering, Federal University of Sao Carlos (UFSCar), Brazil, clarissa.biotto@ufscar.br, orcid.org/0000-0002-2433-6735

3 Professor, Civil Engineering Department, Federal University of Sao Carlos (UFSCar), Brazil, sheylabs@ufscar.br, orcid.org/0000-0002-9508-976X 
lifespan, and high repair costs that could be avoided. According to the Brazilian Institute of Assessments and Engineering Expertise of São Paulo - IBAPE /SP (2015), more than $60 \%$ of buildings' accidents are caused by failures in maintenance and use.

In this context, maintenance management is responsible for planning, controlling, and executing building maintenance. However, the traditional management methods are no longer indicated, as they have not followed the evolution of buildings, which tend to have larger dimensions, especially vertically, besides existing more complex equipment and technologies that serve an increasing number of users (Abreu, Calado, and Requeijo, 2016). Thus, the importance of having more efficient maintenance has been demonstrated through recent studies that try to relate lean thinking with maintenance strategies, as claim Mostafa and Soltan (2014).

The lean philosophy aims to reduce activities or services that do not add value to the customer (user), and despite its initial development in the industrial environment, it can be applied in the service sector. Hence, it emerges the focus on lean maintenance, which still lacks studies on the drivers and barriers of implementation and its benefits for the building maintenance sector.

Therefore, through a case study, this paper proposes to identify the lean maintenance management principles and practices used by a company responsible for the building maintenance and in which conditions they are applied.

\section{LITERATURE REVIEW}

\section{Building Maintenance Management}

To ensure that the buildings and systems meet their functional capability,requirements and users' safety, it is necessary to apply a set of conservation or recovery activities, called maintenance (ABNT NBR 5674, 2012). It ensures that the building complies with standards and laws (Abreu, Calado, and Requeijo, 2016). The maintenance system is the "set of procedures organised to manage maintenance services". It aims to preserve the building's original characteristics and prevent its loss of performance defined in the design, resulting from the degradation of its systems, elements, and components (NBR 5674 ABNT, 2012).

The usual functions of the building maintenance management are preparation of plans, procedures, and routines of maintenance, operation of equipment and building facilities, manage works, documentation of the building and related equipment, human and material resources, contracts of external service providers, and prepare maintenance budget ensuring rationalisation and cost control (NBR 5674 ABNT, 2012; Abreu, Calado and Requeijo, 2016). In addition, the BMM must perform preventive, corrective and routine maintenance activities (NBR 5674 ABNT, 2012).

\section{Lean Principles and Waste in Maintenance Management}

The five lean principles proposed by Jones and Womack (1996) are the same in maintenance aspects (Davies and Greenough, 2010, Mostafa, Dumrak, and Soltan, 2015). Moreover, Pinto (2013) describes these five principles from the lean maintenance perspective as:

1. Identify the value: what the customer expects with maintenance, zero breakdowns, zero accidents, zero costs, sustained increase in efficiency in operations, among others;

2. Map the value stream: identify which are the steps within maintenance that deliver value to the customer; 
3. Create a continuous flow of value: improving information, material and people flows in order to accelerate value creation processes by eliminating waste;

4. Establish pull: perform tasks only when necessary within the management of reserve materials, supplier management, and communication;

5. Seek perfection: encourage maintenance employees to improve performance with the adoption of systematic tools and methodologies that promote proactive practices and attitudes towards maintenance in order to eliminate activities that add time and cost;

Specifics actions should be taken to achieve the lean maintenance principles. For value definition, the organisational maintenance system must be define, including activities, planning, team, and training of those involved (Mostafa, Dumrak, and Solta, 2015). In identifying the value stream, the authors suggest mapping the maintenance value stream (current state), identifying waste in all activities and processes related to maintenance, and defining the performance measures of maintenance elements (Mostafa, Dumrak, and Solta, 2015).

In sequence, to create a continuous flow of value are the analysis of networks and waste practices, prioritisation of removing these, and documentation of gaps in the current state of maintenance management. Subsequently, it is recommended to reconfigure the value stream map (future state) with the selection of best lean practices, followed by the simulation and execution of lean maintenance that should have its overall effectiveness evaluated, thus configuring the step of applying the pull logic (Mostafa, Dumrak and Solta, 2015).

Finally, Mostafa, Dumrak, and Soltan (2015) suggest auditing lean maintenance results, creating standardisation of lean practices and procedures, developing teams and employees, and expanding lean practices to seek perfection in all processes.

Specifically for the maintenance of buildings, Abreu, Calado, and Requeijo (2016) propose applying lean philosophy in four phases/pillars based on the elimination of waste and the principles of continuous improvement (seeking perfection) definition/creation of value. The proposal of these authors, named Lean Building Maintenance (LBM), can be seen in Figure 1.

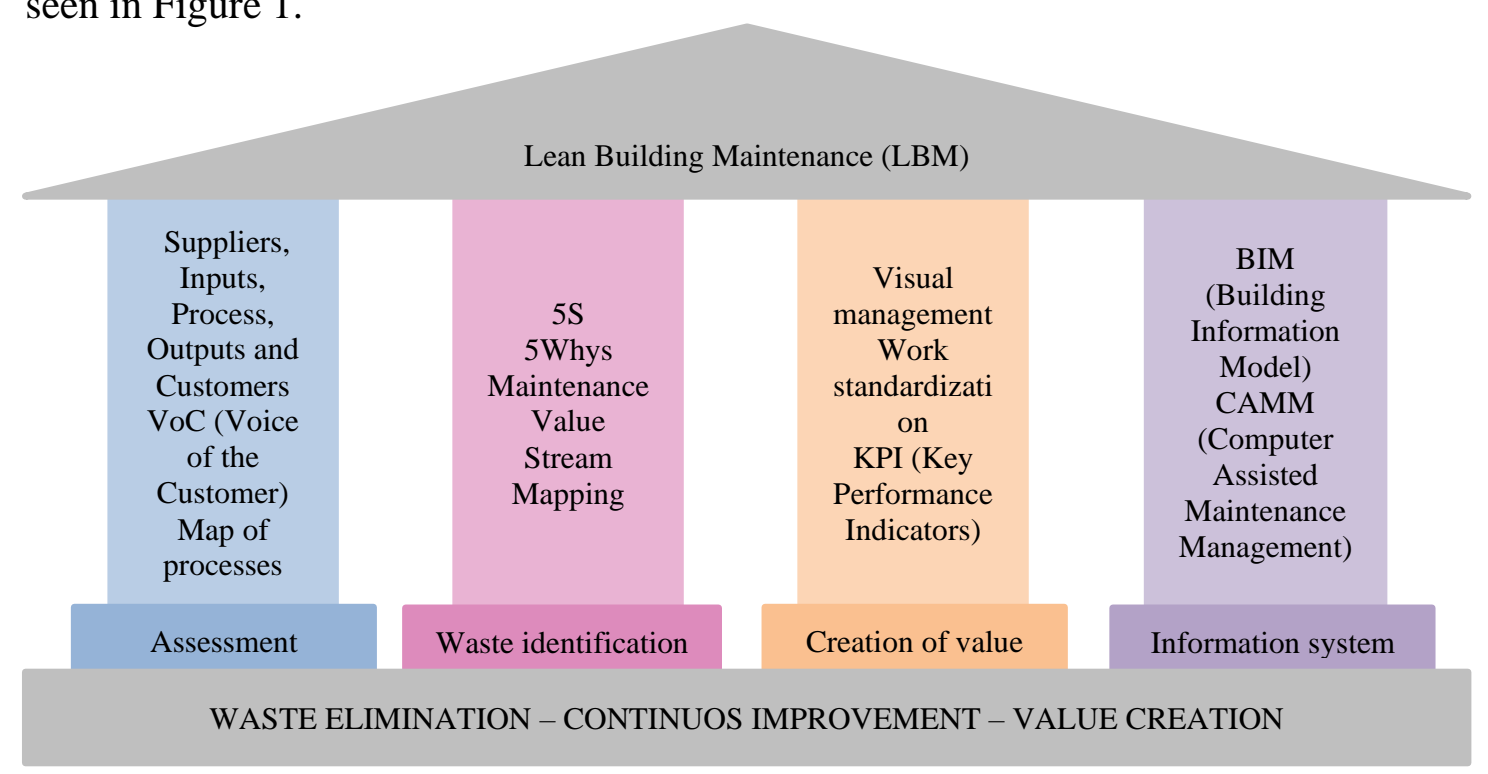

Figure 1: Lean Building Maintenance House (adapted from Abreu, Calado, and Requeijo, 2016) 
The first phase/pillar of Figure 1 aims to evaluate the organisation's state and knowledge to obtain the diagnosis of the most accurate current state possible. The second aims to identify waste, such as activities that do not add value to the organisation and suggest improvements. Thus, the actions of the first and second phase of this proposal include the actions related to the principles "1. Identify value", "2. Map the value stream", and "3. Create a continuous flow" from the previous proposal.

The third stage resembles the stage that addresses the fourth and fifth principles of the previous proposal, which are, respectively, "4. Establish pull" and "5. Seek perfection". In this stage, after applying suggested lean tools and practices, the objective is to expose the value creation to the organisation by measuring the impact of the implemented improvements and the elaboration of standardisation of practices.

Finally, the fourth stage/pillar aims to implement a computerised system to support decision-making and enable a more efficient administration of the volume of information required to manage activities.

To achieve the objective of each phase, the authors propose tools that are exposed in

Figure 1 in their respective pillars.

\section{The 8 Wastes in Maintenance}

The wastes within maintenance are proposed by different authors based on the original wastes defined by Ohno (1997). Within the bibliography, the proposals that most closely resemble each other are Pinto (2013), Clarke, Mulryan, and Liggan (2010), and Mostafa, Dumrak, and Soltan (2015). For Pinto (2013), the eight maintenance wastes are:

1. Unproductive work - performing activities that do not add value, such as unnecessarily performing preventive maintenance tasks or at intervals smaller than what is necessary;

2. Rework - incorrect performance of tasks that must be redone;

3. Waiting for resources - long periods of inactivity due to the lack of availability of materials, workforce, equipment, or information to accomplish the task;

4. Poor inventory management - not having or having excess material to perform the tasks;

5. Excessive transportation - an excessive movement of materials and information due to the unavailability of documentation and work orders and provision of resources away from work areas;

6. Waste by movement - loss of time in round trips due to the lack of an appropriate and unique place for the disposal of materials and documentation that are essential to the performance of maintenance services;

7. Ineffective data management - a collection of information that is not necessary, absence of vital data collection or inefficiency in data collection due to the lack of interconnection of this data with maintenance processes, e.g., with inspections;

8. Under utilisation of resources - an absence of the maximisation of resources is material or human, being the human exemplified by the non-use of such a skill set.

Clarke, Mulryan, and Liggan (2010) present the "incorrect application of machinery", which would be the incorrect operation of tools or choice of operational strategies that apply unnecessary maintenance services. Mostafa, Dumrak, and Soltan (2015) present in the "maintenance without the standard", as the operations are done as quickly as possible, 
without guidelines and standard procedures, eliminating the opportunity to perform a higher quality repair.

\section{LeAn Practices AND ToOLS}

Lean tools represent applying the principles during this philosophy's implementation (Mostafa, Dumrak, and Soltan, 2015). Among the various existing tools, those that cover maintenance activities are: 5S; 5Whys; Total Production Management (TPM); Kaizen; Poka-Yoke; Kanban; Process Mapping (PM); Computerized Maintenance Management System (CMMS)/Computer-Aided Maintenance Management (CAMM); Just In Time; Failure Mode and Effect Analysis (FMEA); standardisation of procedures; Value Stream Mapping (VSM); Visual Management (Smith, 2004, Davies, Davies and Greenough, 2010, Mostafa, 2015, Abreu, Calado and Requeijo, 2016).

Building Information Model (BIM) can also help organisations manage maintenance information (Mostafa, Dumrak, and Soltan, 2015). Furthermore, PM differs from VSM by focusing on individual processes rather than material flows and product-related information. Also, the future state view of a Process Map is defined in noticeable improvements and does not consider lean principles such as VSM (Ferro, 2005).

\section{RESEARCH METHOD}

The research strategy adopted was the case study in a building maintenance company. It was developed a lean maintenance checklist for data collection with the study's participants.

\section{Data Collection}

The literature review was the basis for structuring the initial data collection tool, mainly NBR 5674 (ABNT, 2012) and lean principles. It was developed in joint with the participating company as a research protocol to diagnose their processes and understand the maintenance activities flow. Furthermore, the protocol inspired the tool for conducting qualitative exploratory research based on the method proposed by Toledo and Shiaishi (2009).

The final version of the checklist was divided into three parts: characterisation of the company and interviewees; identification of procedures, activities, tools, and practices used in maintenance management through lean maintenance principles (criteria). A set of best practices has been established for each principle of lean maintenance (criteria) based on the bibliographic review. This third part of the checklist (Table 1) contains 46 items to evaluate lean maintenance principles.

It is noteworthy to mention that the data collection was performed remotely through videoconferencing tools due to the social distance imposed by the Covid-19 pandemic. The application of the questionnaire had a duration of one and a half hours on average. The interviewee was the Maintenance Manager of the studied company, and it was not requested that he knew lean concepts.

\section{Data Analysis Method}

The data analysis was based on the method proposed by Saurin and Ferreira (2008), in which the criteria are analysed individually, qualitative, and quantitatively. Each lean principle, i.e., criterium, of the checklist had a total score resulted by the sum of each practices' scores. The researchers attributed the score according to the lean practice level in maintenance management (see Table 2). 
Table 1: Checklist for the evaluation of lean maintenance principles in buildings

\begin{tabular}{|c|c|}
\hline 1 & Identify the value \\
\hline 1.1 & There is a maintenance plan \\
\hline 1.2 & The maintenance plan is periodically reviewed \\
\hline 1.3 & $\begin{array}{l}\text { There is a standardised protocol/process for supplier } \\
\text { management }\end{array}$ \\
\hline 1.4 & $\begin{array}{l}\text { Is there a system for identifying the opinion, need and } \\
\text { preferences of the end customer (VoC) }\end{array}$ \\
\hline 1.5 & Pre-site inspections are carried out periodically \\
\hline 1.6 & $\begin{array}{l}\text { End customers (users) are oriented on proper use and } \\
\text { emergencies }\end{array}$ \\
\hline 1.7 & $\begin{array}{l}\text { Maintenance personnel are trained to learn about the } \\
\text { philosophy, principles, and basic practices of lean } \\
\text { maintenance }\end{array}$ \\
\hline 1.8 & $\begin{array}{l}\text { There is a computerised system for information } \\
\text { management }\end{array}$ \\
\hline 2 & Map the value stream \\
\hline 2.1 & There is a map of maintenance processes \\
\hline 2.2 & $\begin{array}{l}\text { There is a map of the current state of the maintenance } \\
\text { process }\end{array}$ \\
\hline 2.3 & $\begin{array}{l}\text { A team draws up the current state map with } \\
\text { representatives from each part of the process }\end{array}$ \\
\hline 2.4 & There are indicators for maintenance management \\
\hline 2.5 & There are evaluation and review of the indicators of the \\
\hline 2.6 & $\begin{array}{l}\text { Area indicators and metrics are disseminated to all } \\
\text { employees }\end{array}$ \\
\hline 2.7 & $\begin{array}{l}\text { The use of visual devices is disseminated for the sharing } \\
\text { of information }\end{array}$ \\
\hline 2.8 & $\begin{array}{l}\text { There is a computerised system for information } \\
\text { management }\end{array}$ \\
\hline 3 & Create continuous value flow \\
\hline 3.1 & $\begin{array}{l}\text { There is a future state map, and action plans to } \\
\text { implement it }\end{array}$ \\
\hline 3.2 & $\begin{array}{l}\text { A team with representatives from each part of the } \\
\text { process analyses the map of the current state and } \\
\text { elaborates the future state }\end{array}$ \\
\hline 3.3 & $\begin{array}{l}\text { Structured tools are used for analysis and waste } \\
\text { solution, such as } 5 \text { Whys, fishbone diagram, or } \\
\text { brainstorming }\end{array}$ \\
\hline 3.4 & There is an application of $5 \mathrm{~S}$ or similar programs \\
\hline 3.5 & $\begin{array}{l}\text { There is a preference for preventive maintenance rather } \\
\text { than corrective maintenance }\end{array}$ \\
\hline 3.6 & $\begin{array}{l}\text { There are operation sheets and standard routines to } \\
\text { guide maintenance activities }\end{array}$ \\
\hline 3.7 & There is a maintenance plan \\
\hline 3.8 & $\begin{array}{l}\text { There are specific locations for depositing materials and } \\
\text { searching for information, and these favours the } \\
\text { performance of the activities }\end{array}$ \\
\hline
\end{tabular}

The use of visual devices is disseminated for

3.9 information sharing and visualisation of the process flow from start to finish

3.10 There is the autonomy of employees to perform their

3.10 duties (no need for verification by the highest positions)

4. Establish pull

4.1 There is a computerised system for information

4.1 management

4.2 There are devices to pull process activities

4.3 There are devices to identify the removal of items from the process, such as materials and equipment

If kanban cards are used, the subsequent activity

4.4 removes information from the preceding only in the quantities and in the necessary time

4.5 There are no large stocks

4.6 Supplier deliveries are pulled rather than pushed

4.7 Suppliers deliver in small batches and often Devices for pulling material deliveries contain

4.8 information about what is requested when to arrive, how much, and where it should be stored

4.9 There is an established partnership with suppliers

4.10 There is an established partnership with outsourced services when necessary

5 Seek perfection

5.1 There is an evaluation of the indicators of the area Structured tools are used for analysis and

5.2 troubleshooting, such as PDCA, 5Whys, 5W2H, fishbone diagram, or brainstorming

5.3 Action plans are drawn up for improvements

5.4 Senior management is involved with improvement programs

5.5 New implemented practices are expanded to other activities/processes

5.6 The improvements made are standardised

5.7 Employees participate in the development of standards to incorporate their experiences into them

5.8 The goals and indicators of the area are clearly defined and communicated to all involved

The goals of the area are clearly and objectively

5.9 unfolded so that continuous improvement actions contribute to achieving them Maintenance personnel are trained to learn about the

5.10 philosophy, principles, and basic practices of lean maintenance

Table 2: Parameters for the evaluation of the lean maintenance practices

Parameters Description of the level of application Score

Does not apply (NA)

Does not exist (NE)

Very weak application

(VWA)

Weak application (WA)

Strong application (SA)

Very strong application

(VSA)

the practice is not applied due to the company's characteristics

the practice is not present in the company

the practice has its use started recently in the company or is practised

rarely or for a specific situation

the practice is in use in the company but is applied in a few situations 5,0

the practice is in use in the company and is applied to most situations 7,5

the practice is already fully consolidated in the company and use
0,0

0,0

10,0 
The following equation gives the scores for each lean maintenance principle: $\mathrm{A}$ is the number of applicable practices; $\mathrm{B}$ is the number of very weak application (VWA) practices; $\mathrm{C}$ is the number of weak application (WA) practices; $\mathrm{D}$ is the number of strong application (SA) practices, and $\mathrm{E}$ is the number of very strong application (VSA) practices.

$$
\text { Score }=\frac{(B \times 2,5)+(C \times 5,0)+(D \times 7,5)+(E x 10,0)}{A}
$$

\section{The CaSe Study Company}

The case study was conducted in a maintenance management company located in São Paulo, Brazil. The company was identified in the Brazilian Association of Facilities' (ABRAFAC) register. It is a Brazilian firm founded in 1985, which operates in the industrial maintenance sector, facilities, administration, and logistics, having 35,000 employees in Brazil and Argentina and 300 customers, serving approximately 1500 units in Brazil and 1 in Argentina.

For each new client, a contract is drawn up according to their needs. For the case study, the maintenance company had a fixed maintenance team in the clients' facilities: they served three industrial buildings of approximately 78,000 sqm and ages from 5 to 25 years. The team consisted of nine employees: one maintenance supervisor, one planner, two electricians, one maintenance officer, one maintenance assistant, one refrigeration mechanic, one painter and one builder. In this case, the builder assists other employees and performs the inspection of equipment and systems.

\section{RESULTS - COMPANY'S LEAN MAINTENANCE PRINCIPLES SCORE}

The results of the application of the lean principles in building maintenance management are depicted in Figure 2 there is a score for the practices applied by the maintenance company. The average score of company for the principles is in chart 6 - Figure 2 .
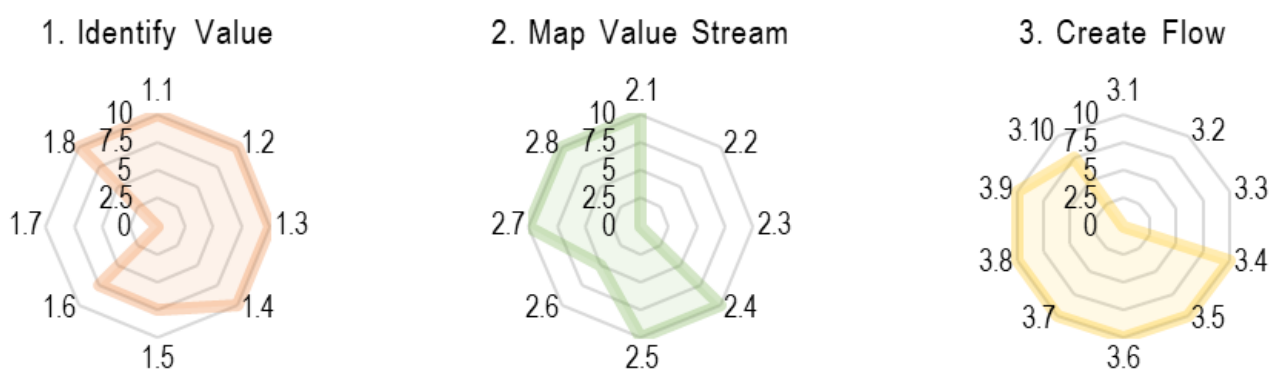

\section{Establish Pull}

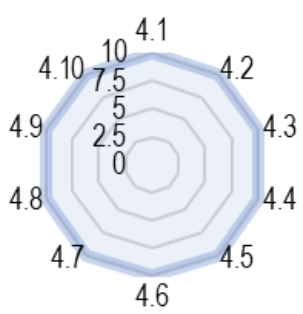

5. Seek Perfection

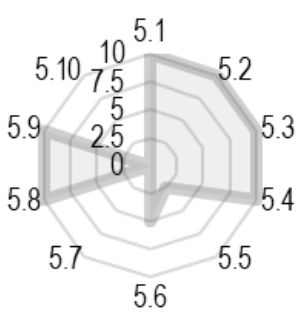

6. Company's final score

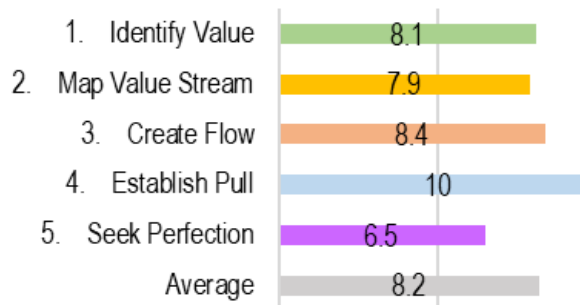

Figure 2: Charts 1 to 5 represent the company's scores in the application of lean principles. Chart 6 is the average score achieved for each principle. 
In principle "1. Define Value" (note 8.1), the company highlighted the application of a customer's satisfaction survey with the periodicity of 6 months, evaluations of corrective work, which is also a metric for management, in addition to a frequent dialogue with the unit manager. These actions indicate a concern with the users' opinions, needs, and preferences. The first two practices are recorded in a computerised management system. It was also detected other relevant practices, such as the maintenance plan; standardised process for suppliers' management; building inspections; and users' guidance regarding the building's use and operation, including emergencies.

It has also been reported that clients invest in preventive maintenance and others who focus only on corrective maintenance. Others require verification of all services performed, making it difficult to flow activities. All these requirements are defined in advance in the contract and are the basis for the service provider's maintenance. In addition, it reveals an identification of the value coming from the contract since all customer/users' preferences are defined.

The principle "2. Map the value stream" (score 7.9) regards disseminating indicators and metrics. The indicators are essential to perform a critical and systemic analysis of the deployed building maintenance management and help identify waste. The company has the following indicators: productivity; the percentage of preventive maintenance execution; the number of orders in "backlog" (orders that were not performed); deviation scheduled vs executed correctives; and the service lead time per order. The tool suggested in the literature review, Value Stream Map, is not applied. However, the company uses the process map, which is disseminated visually by the computerised management system and accessed by all employees through mobile devices, such as smartphones or tablets.

The maintenance plan for each asset also contains standardised maintenance procedures. These procedures support creating a continuous flow of value according to Principle "3. Create Flow" (note 8,4). As a rule, imposed by the contractor, the company applies the $5 \mathrm{~S}$ in the office and warehouse. In addition, the computerised system centralised the maintenance process information, being possible to verify the activities statuses. Also, employees have the autonomy to carry out their activities, and checks are required by the supervisor only when it interferes with safety or essential activities to production.

The principle "4. Establish Pull" reached the maximum score (10.0) since the computerised management system pulls the process activities, besides having a small inventory and partnership with suppliers and subcontractors. In addition, the computerised system records the requested materials by suppliers, their quantities, and the delivery dates.

The principle "5. Seek perfection" (score 6.8) has the lowest evaluation score. It is mainly due to employees' non-participation in the practice's standardisation and the lack of training on lean philosophy. However, other practices of this principle have been implemented, such as the PDCA and the Ishikawa diagram. An example of improvement was implementing the DDS (Daily Dialogue on Safety), reducing about $99 \%$ of accidents.

Due to the lack of training on lean philosophy, the non-participation of employees in the standardisation of practices, and the presentation of goals focused only on individual productivity, and it is evident that there is no involvement of all hierarchical levels in the continuous improvement.

In principles 2 and 5 (Map the value stream and Seek perfection), the deployed process map and indicators do not consider aspects of lean philosophy, such as waste, which would lead to continuous improvements. 
In conclusion, it was verified that the company presented high marks for all the principles of lean maintenance despite not having any specific program of lean. The final score obtained by the company was impacted by the client preferences established in the contract, namely, the level of services quality, the types of maintenance to be performed, level of employees' autonomy, application of $5 \mathrm{~S}$, among other requirements such as monthly presentations of five improvement proposals.

\section{CONCLUSIONS}

Despite the consensus regarding the importance of building maintenance, there are still many buildings in which it is neglected or misunderstood, resulting in risks to its users' safety, no guarantee of the lifespan of the building, and high costs that could be avoided. Maintenance management is responsible for planning, controlling, and executing building maintenance, ensuring compliance with requirements.

Hence, a case study in a building maintenance and management company was carried out to evaluate its lean maintenance practices within its client. Results obtained through the application of a checklist showed that the maintenance management prioritises preventive and predictive maintenance activities and the application of many lean practices and tools, reaching grades between 6.8 and 10.0 and an average of 8.2 for the five lean maintenance principles. Furthermore, the average score was obtained after applying the checklist prepared with the best practices observed in the literature, demonstrating that the company can improve based on lean principles and technical standards for maintenance management.

Several requirements pointed out by NBR 5674 (ABNT, 2012) are framed as good practices of the lean maintenance principles, which contributed to the excellent average obtained. As the company is hired to do maintenance management, it became an expert and started to incorporate some lean practices due to the request and influence of customers/users in the implementation of contracts. This point of outsourcing the service can be considered as a positive impact to achieve a high score.

The organisational culture had also impacted positively on the results regarding the lean practices: the understanding of maintenance and the importance to perform different maintenance types; the application of $5 \mathrm{~S}$; the use of small inventories; the development of partnerships with suppliers and subcontractors. The isolated application of practices and tools does not guarantee the application of lean mentality since critical points such as the involvement of all employees in the improvement processes and the identification of waste and employees' training on lean were not applied in the case study.

Therefore, the lean mentality can help build maintenance management since it is implemented strategically, addressing its concepts and not only practices and tools. However, more important than its implementation is the attention paid to the normative requirements and recommendations of the bibliography for efficient building maintenance management.

\section{ACKNOWLEDGMENTS}

The second author would like to thank Coordenação de Aperfeiçoamento de Pessoal de Nível Superior - Brasil (CAPES), for the PNPD postdoctoral scholarship. 


\section{REFERENCES}

Abreu, A., Calado, J., and Requeijo, J. 2016. "Buildings Lean Maintenance implementation model." Open Engineering, 6(1), 397-406.

Akcamete, A., Akinci, B., and Garrett, J.H. 2010. "Potential utilisation of building information models for planning maintenance activities." In Proc., The International Conference on Computing in Civil and Building Engineering. Nottingham: W Tizani.

Brazilian Association of Technical Standards (Associação Brasileira de Normas Técnicas - ABNT). 2012. NBR 5674: Manutenção de Edifícios - Requisitos para o sistema de gestão de manutenção. Rio de Janeiro: ABNT.

Brazilian Institute of Assessments and Engineering Expertise of São Paulo (Instituto Brasileiro de Avaliações e Perícias de Engenharia de São Paulo - IBAPE/SP). (Ed.2). 2015. "Inspeção Predial: a saúde dos edifícios". São Paulo, Brazil: IBAPE/SP.

Carlino, A.E. 2012. "Melhorias dos processos de manutenção em prédios públicos.” M.Sc. Thesis, Master in Structures and Civil Construction, Federal University of São Carlos, São Carlos.

Clarke, G., Mulryan, G., and Liggan, P. 2010. "Lean Maintenance: a risk-based approach." International Society for Pharmaceutical Engineering, 30(5), 1-6.

Davies, C., and Greenough, R. M. 2010. "Measuring the effectiveness of lean thinking activities within maintenance." 9p. Available in: http://www.plantmaintenance.com/articles/Lean_Maintenance.pdf.

Ferro, J.R. 2005. "A essência da ferramenta Mapeamento do Fluxo de Valor." Lean Institute Brasil. Available in: https://www.lean.org.br/artigos/61/a-essencia-daferramenta-mapeamento-do-fluxo-de-valor.aspx.

Womack, J.P., and Jones, D.T. 1996 "Beyond Toyota: how to root out waste and pursue perfection." Harvard Business Review, 74(5), 140-172.

Lessa, A.K.M.D.C., and H.L. de Souza. (Ed.1). 2010. Gestão da Manutenção Predial: uma aplicação prática. Rio de Janeiro: Qualitymark.

Mostafa, S., Lee, S. H., Dumrak, J., Chileshe, N., and Soltan, H. 2015. "Lean thinking for a maintenance process." Production and Manufacturing Research, 3(1), 236-272.

Mostafa, S., Dumrak, J., and Soltan, H. 2015. "Lean maintenance roadmap." Procedia Manufacturing, 2, 434-444.

Mostafa, S., and Soltan, H. 2014. "Leanness and agility within maintenance process." International Journal of Engineering Research \& Technology, 3(3), 553-555.

Ohno, T.O. 1997. Sistema Toyota de Produção: além da produção em larga escala. Porto Alegre: Bookman.

Pinto, J.P. 2013. Manutenção Lean. Lisbon: Lidel.

Saurin, T.A., and Ferreira, C.F. 2008. "Avaliação qualitativa da implantação de práticas da produção enxuta: estudo de caso em uma fábrica de máquinas agrícolas." Gestão \& Produção, 15(3), 449-462.

Smith, R. 2004. "What is Lean maintenance? Elements that need to be in place for success." Maintenance Technology, 17(10), 15-21.

Toledo, L.A., and Shiaishi, G. de F. 2009. "Estudo de caso em pesquisas exploratórias qualitativas: um ensaio para a proposta de protocolo do estudo de caso." Revista da FAE, 12, 103-109. 